Venous thromboembolism in the critically ill: A prospective observational study of occurrence, risk factors and outcome

\begin{tabular}{|c|c|}
\hline Journal: & Acta Anaesthesiologica Scandinavica \\
\hline Manuscript ID & Draft \\
\hline Wiley - Manuscript type: & Clinical investigation \\
\hline Date Submitted by the Author: & $\mathrm{n} / \mathrm{a}$ \\
\hline Complete List of Authors: & $\begin{array}{l}\text { Beitland, Sigrid; University of Oslo, Institute of Clinical Medicine; Oslo } \\
\text { University Hospital, Department of Anaesthesiology } \\
\text { Wimmer, Henning; Oslo University Hospital, Department of Acute Medicine } \\
\text { Lorentsen, Torleif; Oslo University Hospital, Department of Anaesthesiology } \\
\text { Jacobsen, Dag; Oslo University Hospital, Department of Acute Medicine } \\
\text { Drægni, Tomas; Oslo University Hospital, Department of Research and } \\
\text { Development } \\
\text { brunborg, cathrine; Oslo University Hospital, Unit of Biostatistics and } \\
\text { Epidemiology } \\
\text { Kløw, Nils Einar; University of Oslo, Institute of Clinical Medicine; Oslo } \\
\text { University Hospital, Department of Radiology } \\
\text { Sandset, Per Morten; University of Oslo, Institute of Clinical Medicine; Oslo } \\
\text { University Hospital, Department of Haematology } \\
\text { Sunde, Kjetil; Oslo University Hospital, Department of Anaesthesiology; } \\
\text { University of Oslo, Institute of Clinical Medicine }\end{array}$ \\
\hline Key Words: & $\begin{array}{l}\text { Venous thromboembolism, Critical illness, Venous thrombosis, Pulmonary } \\
\text { embolism }\end{array}$ \\
\hline Subject area: & Intensive Care Medicine \\
\hline
\end{tabular}


Title

\title{
Venous thromboembolism in the critically ill: A prospective observational study of occurrence, risk factors and outcome
}

\author{
Names ot the authors \\ Sigrid Beitland ${ }^{1,2}$, Henning Wimmer ${ }^{3}$, Torleif Lorentsen ${ }^{2}$, Dag Jacobsen ${ }^{1,3}$, Tomas Drægni ${ }^{4}$, \\ Cathrine Brunborg ${ }^{5}$, Nils Einar Kløw ${ }^{1,6}$, Per Morten Sandset ${ }^{1,7}$, Kjetil Sunde $^{1,2}$ \\ Name and location of the institution where the work was carried out \\ ${ }^{1}$ Institute of Clinical Medicine, University of Oslo, Oslo, Norway \\ ${ }^{2}$ Department of Anaesthesiology, Oslo University Hospital, Oslo, Norway \\ ${ }^{3}$ Department of Acute Medicine, Oslo University Hospital, Oslo, Norway \\ ${ }^{4}$ Department of Research and Development, Oslo University Hospital, Oslo, Norway \\ ${ }^{5}$ Oslo Centre for Biostatistics and Epidemiology, Oslo University Hospital, Oslo, Norway \\ ${ }^{6}$ Department of Radiology, Oslo University Hospital, Oslo, Norway \\ ${ }^{7}$ Department of Haematology, Oslo University Hospital, Oslo, Norway
}

\section{Short title}

Venous thromboembolism in the ICU

\section{Word count \\ 2775}

\section{Corresponding author}

Sigrid Beitland, $\mathrm{MD}, \mathrm{PhD}$, Postdoctoral researcher

Institute of Clinical Medicine, University of Oslo, P.O.Box 1072 Blindern, 0316 Oslo,

Norway

E-mail: sigrid.beitland@medisin.uio.no, telephone: +4722119585, telefax: +4722119634

\section{Conflict of interest}

The authors declare that they have no conflict of interest in relation to this manuscript. 


\section{Abstract}

Background The aim of the study was to explore occurrence, risk factors and outcome of venous thromboembolism (VTE) in intensive care unit (ICU) patients.

Methods Prospective observational study of ICU patients receiving thromboprophylaxis at Oslo University Hospital in Norway. Adult medical and surgical patients with ICU length of stay (LOS) longer than 48 hours were included. For detection of VTE, Doppler ultrasound screening of neck, upper and lower extremity veins was used, and computed tomography angiography when clinically indicated for any medical reason.

Results Among 70 included patients, $79 \%$ were males and mean age was $62( \pm 12.1)$ years. All received thromboprophylaxis with dalteparin, and 44 (63\%) used graduated compression stockings. VTE was found in 19 (27\%) patients; deep vein thrombosis in 15 (21\%) and pulmonary embolism in four (6\%). Among the VTEs, $11(58 \%)$ presented within the first 48 hours after admission, nine (47\%) were related to central vein catheters, and five (26\%) were symptomatic. Risk factors for VTE in multivariable analyses were malignancy, abdominal surgery and SAPS II score $<41$ with an AuROC (95 \% CI) of $0.72(0.58-0.85, \mathrm{p}=0.01)$. Patients with and without VTE had comparable ICU LOS (13 vs. 11 days, $p=0.27$ ) and mortality (16 vs. $20 \%, p=0.72)$.

Conclusion VTE was observed in $27 \%$ of ICU patients receiving thromboprophylaxis. Factors associated with increased risk of VTE were malignancy, abdominal surgery and SAPS II score $<41$. Presence of VTE did not impact on patient outcome. 


\section{Introduction}

Patients in the intensive care unit (ICU) may suffer from venous thromboembolism (VTE) being deep vein thrombosis (DVT) and/or pulmonary embolism (PE) [1]. Such VTE may be present at admission, or develop during the later ICU stay. VTE occurrence depends on the study population, use of thromboprophylaxis, and diagnostic method utilised to detect DVT and PE. Among known risk factors are genetic disposition, advanced age, immobilisation and surgery [2]. Presence of VTE is associated with adverse outcome, especially PE is considered to be an important cause of preventable morbidity and mortality among ICU patients [3-6]. Recent guidelines therefore recommend initiation of combined pharmacological and mechanical thromboprophylaxis as soon as considered safe [7-8].

Limited data from ICU patients suggest that DVTs often occur in other locations than the lower extremities [9, 10], and/or related to central venous catheters (CVCs) [11, 12]. Many VTEs in ICU patients are not clinically suspected, since clinical features may be absent or difficult to distinguish from other conditions. Such asymptomatic VTE may include DVTs found during Doppler ultrasound (DUS) screening of veins [13, 14], unsuspected PEs observed during autopsy [15], in addition to VTEs found during computed tomography (CT) angiography examinations. An unsettled issue is treatment of VTEs in the ICU, as anticoagulant therapy is challenging due to increased risk of bleeding among critically ill patients already exposed to bleeding complications. It is also uncertain whether catheterrelated DVTs should be treated with removal of the catheter.

The purpose of the present study was to assess VTE in medical and surgical high-risk ICU patients receiving thromboprophylaxis. The primary aim was to explore occurrence, risk factors and outcome of VTE. Secondary aims were to describe the observed VTE in terms of location, catheter-relation, symptomatology and treatment. 


\section{Methods}

\section{Study design and setting}

The study was a prospective observational study entitled Norwegian Intensive Care Unit Dalteparin Effect Study (NORIDES study) and the patients were enrolled consecutively. Oslo University Hospital is a community hospital for Oslo, and a regional hospital for 2.7 million people in South-Eastern Norway. The Regional Committee for Medical and Health Research Ethics approved the study (approval number 2012/924). The study was registered at ClinicalTrials.gov (NCT01721928).

\section{Study population}

Inclusion criteria were medical and surgical ICU patients at Oslo University Hospital receiving pharmacological thromboprophylaxis with dalteparin (Fragmin, Pfizer, NJ, USA) between December 2, 2012, and March 2, 2016. Exclusion criteria were age $<18$ years, intraocular or intracranial bleeding, acute spinal cord lesion, inherited coagulopathy, uncontrolled bleeding, therapeutic anticoagulation, uncorrected coagulopathy, pregnancy or postpartum ( $<6$ weeks), participation in an interventional study, chronic kidney disease and anticipated ICU length of stay (LOS) $<48$ hours. All included patients received pharmacological thromboprophylaxis with dalteparin. Standard dose was subcutaneous dalteparin $5000 \mathrm{IU} /$ day, but this could be altered based on individual risk assessment. Mechanical prophylaxis consisted of bilateral graduated compression stockings (GCS); this was routinely used in the surgical ICU, but not in the medical ICU. The initial goal of the study was to compare patients with acute kidney injury (AKI) treated with continuous renal replacement therapy (CRRT) with a control group of patients having normal kidney function. Enrolment of patients was therefore performed in order to obtain equal number of patients with and without severe AKI treated with CRRT, but enrolment was much lower than 
expected. Since the study was underpowered in order to compare VTE occurrence in patients with and without severe AKI, we here present descriptive data on VTE in the ICU. In patients undergoing CRRT, the haemodialysis circuit was regionally anticoagulated with citrate (Multifiltrate, Fresenius Medical Care, Bad Homburg, Germany).

\section{Study definitions}

Comorbidities were classified according to the Charlson comorbidity index [16]. Severity of illness was assessed using the Simplified Acute Physiology Score (SAPS II) [17] and Sequential Organ Failure Assessment (SOFA) score [18]. Risk factors for VTE included most mentioned in the American College of Chest Physicians (ACCP) guidelines [2], and additional ICU risk factors such as the use of intravenous catheters, low-dose dalteparin (mean dose $<5000$ IU/day) and low-dose GCS (mean duration of GCS use $<20$ hours/day). AKI was defined according to the Kidney Disease - Improving Global Outcome (KDIDO) criteria [19]. Data on DVT and PE occurrence were collected as outlined in the data collection section. VTE present at admission was defined as DVT and/or PE diagnosed within 48 hours after ICU admission. DVT was classified as catheter-associated if an intravenous catheter was or had been placed in the same vein as the detected thrombus during the ICU stay. VTEs were considered symptomatic when clinicians ordered a radiological examination with the intention to detect DVT or PE.

\section{Data collection}

The main outcomes were DVTs and PEs diagnosed by DUS or CT angiography [20, 21]. Screening of veins for DVT was performed within 48 hours after ICU admission and thereafter twice a week until discharge from ICU or up to 30 days. We used a GE Healthcare Logic 8 (GE Medical Systems, Wisconsin, USA) DUS scanner with 4.0-10.0 MHz probes. 
Signs of DVT included non-compressible or partly compressible vein, presence of luminal echo, and/or loss of colour Doppler. Both internal jugular, subclavian, axillary, brachial, common femoral, superficial femoral, greater saphenous and popliteal veins were examined. Additional VTEs were found during CT angiography ordered when clinically indicated for any medical reason, and no screening method for PE was used. All VTE events were confirmed by the radiologists on call, of whom none were part of the study group.

\section{Statistical methods}

Data are presented as number (percentage), median (interquartile range (IQR)) or mean (standard deviation (SD)). Continuous variables were compared using the Mann-Whitney U test for skewed data, or independent sample t-test for normally distributed data. Univariate analyses of categorical data were performed using the Pearson's Chi square test, and Fisher's exact test when appropriate. The association between potential risk factors and the VTE were quantified by odds ratio (OR) with $95 \%$ confidence interval $(\mathrm{CI})$. Variables with $\mathrm{p}<0.25$ in the univariate analyses were considered candidates for the multivariate model. Independent risk factors were identified using a multivariate logistic regression model and a manual backward stepwise elimination procedure. Multivariate analyses were preceded by estimation of correlation between risk factors. Evaluation of the predictive accuracy of the models was assessed by calibration and discrimination. Calibration was evaluated by the Hosmer and Lemeshow goodness-of-fit test. A statistically non-significant Hosmer and Lemeshow result $(p>0.05)$ suggests that the model predicts accurately on average. Discrimination was evaluated by analysis of the area under the receiver operating characteristics curve (AuROC), acceptable discriminatory capability was defined as an AuROC above 0.7. Statistical analyses were performed using SPSS 23 for Windows (Armonk, NY, USA: IBMCorp), two-sided pvalues less than 0.05 were considered statistically significant. 


\section{Results}

\section{Patient characteristics}

A total of 2419 patients were admitted to the medical or surgical ICU during the study period. Among these, 2140 were excluded due to age $<18$ years $(n=4)$, intracranial bleeding $(n=179)$, acute spinal cord lesion $(n=25)$, inherited coagulopathy $(n=8)$, uncontrolled bleeding $(n=34)$, therapeutic anticoagulation $(n=148)$, uncorrected coagulopathy $(n=7)$, pregnancy or postpartum $(<6$ weeks $)(n=12)$, participation in an interventional study $(n=1)$, chronic kidney disease $(n=77)$ or anticipated ICU LOS $<48$ hours $(n=1645)$. Additional five patients were

Figure 1 excluded from further analysis due to ICU LOS $<48$ hours. Among the 70 studied ICU patients (Figure 1), $79 \%$ were males, mean age was $62( \pm 12.1)$ years, and $50(71 \%)$ had a surgical reason for admission. All patients received VTE thromboprophylaxis with dalteparin, and 44 (63\%) used GCS. CVCs were present in all patients, and additionally 35 (50\%) had a haemodialysis catheter for renal replacement therapy (RRT). Low-dose dalteparin was used in 15 out of 59 (25\%), whereas low-dose GCS was used in 22 out of 59 (37\%) (Table 1). There was no loss to follow-up.

\section{Presence of VTE}

Table 1 VTE was observed in 19 (27\%) patients; DVT in $15(21 \%)$ and PE in four (6\%), respectively. VTE was present within 48 hours after ICU admission in 11 (16\%) patients, and developed later during the ICU stay in another eight (11\%) (Table 1). Time from ICU admission to detection of VTE was median two days, ranging from zero to 20 days. The method used to detect VTE was DUS in $11(16 \%)$ and CT angiography in eight (11\%). 


\section{Risk factors for VTE}

Many potential risk factors for VTE were identified in the univariate analysis (Table 1).

Patients with and without severe AKI treated with CRRT and had similar rate of VTE, although they received comparable pharmacological and mechanical prophylaxis (data not presented). Parameters excluded from the multivariate analysis were trauma, previous VTE and intravenous catheters placed in the internal jugular vein due to zero observations in some

Table 2 of the groups. In multiple logistic regression analysis, malignancy (OR 4.1, 95 \% CI 0.9-18.1, $\mathrm{p}=0.06)$, abdominal surgery (OR 2.0, $95 \%$ CI 0.6-6.5, $\mathrm{p}=0.26)$ and SAPS II score $>41$ (OR 0.4, $95 \%$ CI 0.1-1.2, $\mathrm{p}=0.09$ ) were independent risk factors for VTE (Model II, Table 2). Abdominal surgery was included in the final model although not statistically significant because of a large effect (OR 2.0) and few patients in the study. The Hosmer and Lemeshow goodness-of-fit test was not significant, indicating a satisfactory fit of the model $\left(\chi^{2}=3.3\right.$,

Figure $2 \mathrm{p}=0.51)$. In the best predictive model, AuROC $(95 \% \mathrm{CI})$ was $0.72(0.58-0.85, \mathrm{p}=0.01)$ indicating an acceptable discriminative ability between patients with and without VTE (Model II, Figure 2).

\section{Effects of VTE on patient outcome}

Patients with and without VTE had comparable ICU LOS (13 versus (vs.) 11 days, $p=0.27$ ) and mortality (16 vs. $20 \%$, p=0.72) (Table 1 ). Among the 13 patients that died during their ICU stay, one died due to PE without associated DVT, but none due to bleeding.

\section{Secondary outcomes}

Figure 3 The location of VTE events are presented in Figure 3, two PEs were lobar and two were segmental. Nine DVTs were related to intravenous catheters placed in the right internal jugular vein. When comparing DVTs related to intravenous catheters and not, the catheter- 
related VTEs developed later during ICU stay ( 5 vs. 1 days, $p=0.03$ ), was more often located in the internal jugular vein ( 100 vs. $0 \%$, p $<0.01)$, detected by DUS screening ( 89 vs. $30 \%$, $\mathrm{p}=0.02)$, asymptomatic ( 100 vs. $50 \%, \mathrm{p}=0.03)$ and treated with removal of the catheter $(78$ vs. $0 \%, \mathrm{p}<0.01)$ (Appendix S1).

VTE was symptomatic in five (26\%) of the patients with VTE; three with PE and two with DVT. Symptomatic compared to asymptomatic VTE was more often PE (60 vs. 7 \%, $\mathrm{p}=0.04)$, and more seldom located in the internal jugular vein ( 0 vs. $64 \%, \mathrm{p}=0.03)$ and catheter-related ( 0 vs. $64 \%, \mathrm{p}=0.03)$ (Appendix S2).

Therapeutic anticoagulation was used in 15 (79\%) diagnosed with VTE, including all with PE. In seven out of nine (78\%) patients with catheter-related DVT, the catheters were removed. VTE events present within 48 hours after admission was more often treated with removal of the catheter compared to VTEs developing during the later ICU stay ( 9 vs. $75 \%$, $\mathrm{p}=0.01)($ Appendix S3). 


\section{Discussion}

In this study VTE was found in $27 \%(21 \%$ DVT, $6 \%$ PE) of high-risk ICU patients despite thromboprophylaxis. Further, VTE was already present within 48 hours after ICU admission in more than half of the patients with VTE. Factors associated with increased risk of VTE were malignancy, abdominal surgery and SAPS II score $<41$, but not severe AKI treated with CRRT. There were no differences in mortality or LOS in patients with and without VTE, although one patient died from the PE. Many of the VTEs were catheter-related, located in the neck and upper extremity veins, and asymptomatic.

Previous findings indicate that approximately $5 \%$ of ICU patients have DVT already at admission [22, 23], and additionally 5-15\% of those receiving thromboprophylaxis develop DVT during the later ICU stay [23]. PE is more infrequent, and reported to be present in approximately $2 \%$ of ICU patients [24]. However, many PEs may be overlooked as shown in a post-mortem study where $6 \%$ had undiagnosed PE [25]. We found comparable VTE occurrence in our study, but we might assume that the frequency of PE was underestimated since we did not use screening methods to detect PE.

In agreement with previous studies, we found that patients with malignancy had increased risk of VTE [2]. Abdominal surgery may be associated with VTE in the present study because most such operations were performed due to abdominal malignancy. In contrast to a previous study, we observed that low severity of illness was related to an increased risk of VTE [26]. We also found that patients with and without severe AKI treated with CRRT had similar rates of VTE. This is interesting, since it remains uncertain to what extent presence of severe AKI may alter bleeding and thrombosis risk in ICU patients [27, 28].

DVTs are considered important since emboli are believed to arise from veins, follow the bloodstream, and result in PEs causing haemodynamic compromise and hypoxemia. In previous studies, presence of VTE in ICU patients has been associated with protracted 
duration of mechanical ventilation and prolonged ICU and hospital LOS [3, 29, 30]. A large study of thromboprophylaxis in the ICU also revealed that PE was associated with increased mortality [29]. However, in the present relatively small study, patients with and without VTE had comparable outcome, both related to LOS and mortality.

Most VTEs in our study were located in neck and upper extremity veins, and many were related to intravenous catheters. Such catheter-related thrombosis has been observed in 2-69 \% of CVCs placed in ICU patients $[1,29]$, with the risk of associated PE being 7-17 \% $[31,32]$. The femoral vein seems to be a high-risk location for catheter-associated DVTs in the ICU $[33,34]$. As in a recently published study [11], we observed that the internal jugular vein had most catheter-related DVTs. This finding might be important since internal jugular vein thrombosis previously has been associated with high mortality and morbidity rates in ICU patients $[10,35]$.

Asymptomatic VTEs are common in ICU patients, with a reported variation from 10$100 \%$ for DVT $[13,36]$ and $19-24 \%$ for PE $[37,38]$. Concordantly, we observed that most VTE events in the present study were asymptomatic; especially the DVTs were infrequently clinically suspected. The importance of such asymptomatic VTE is uncertain, with lack of treatment guidelines. Indeed, we need future clinical studies evaluating the efficacy and safety of anticoagulant therapy for asymptomatic VTE in the ICU.

Treatment of VTE in ICU patients is challenging, since major bleeding affects approximately $6 \%$ of those receiving pharmacological thromboprophylaxis [24]. The risk of thrombosis propagation, embolization and acute right ventricular failure must be balanced against the risk of bleeding. PE has a high mortality rate, especially when associated with acute heart failure or circulatory shock [39]. There is evidence showing that anticoagulant therapy reduces mortality in acute PE [40], but treatment of sub-segmental PE is controversial 
[41]. Among our patients, therapeutic anticoagulation was prescribed in all patients diagnosed with PE, but not in everyone with DVT.

This study has limitations. First, our thromboprophylaxis management was not fully standardised, including differences between the medical and surgical ICU. Additionally, some VTE events may have been missed since we did not use screening methods to detect PE. The observed association between risk factors and outcome does not necessarily imply a causal relationship. Further, we were unable to include some relevant risk factors in the multivariate analysis due to zero observations in some of the groups. The study also has a limited sample size, and probably restricted external validity. Finally, our study population is not representative for average ICU patients, since we selected patients with prolonged LOS including many with severe AKI. Strengths of the study are that compared patients came from the same cohort and time period, with no loss to follow-up. Both patient-related and ICUrelated risk factors were assessed, and DVT screening was performed frequently examining many veins.

In conclusion, VTE was observed in $27 \%$ of high-risk ICU patients receiving thromboprophylaxis. Most of the VTE events were DVTs in other locations than the lower extremities, being present early after ICU admission. Factors associated with increased risk of VTE were malignancy, abdominal surgery and SAPS II score $<41$. Patients with and without VTE had similar mortality and LOS. Many of the VTEs were catheter-related and asymptomatic; their clinical importance and treatment warrant future studies.

\section{Acknowledgement}

Financial support was provided solely from institutional sources. The authors declare that they have no conflict of interest in relation to this manuscript. 


\section{Appendices}

\section{Appendix S1}

Table with comparison of VTE related to intravenous catheters and not. The file consists of baseline data, risk factors, VTE characteristics and patient outcome.

\section{Appendix S2}

Table with comparison of symptomatic and asymptomatic VTE. The file consists of baseline data, risk factors, VTE characteristics and patient outcome.

\section{Appendix S3}

Table with comparison of VTE present at admission and developing during ICU stay. The file consists of baseline data, risk factors, VTE characteristics and patient outcome. 


\section{References}

1. Minet C, Potton L, Bonadona A, Hamidfar-Roy R, Somohano CA, Lugosi M, Cartier JC, Ferretti G, Schwebel C, Timsit JF. Venous thromboembolism in the ICU: main characteristics, diagnosis and thromboprophylaxis. Crit Care 2015;19:287.

2. Holbrook A, Schulman S, Witt DM, Vandvik PO, Fish J, Kovacs MJ, Svensson PJ, Veenstra DL, Crowther M, Guyatt GH. Evidence-based management of anticoagulant therapy: Antithrombotic Therapy and Prevention of Thrombosis, 9th ed: American College of Chest Physicians Evidence-Based Clinical Practice Guidelines. Chest 2012; 141:Suppl 1:152-84.

3. Cook D, Crowther M, Meade M, Rabbat C, Griffith L, Schiff D, Geerts W, Guyatt G. Deep venous thrombosis in medical-surgical critically ill patients: prevalence, incidence, and risk factors. Crit Care Med 2005;33:1565-71.

4. Kroegel C, Reissig A. Principle mechanisms underlying venous thromboembolism: epidemiology, risk factors, pathophysiology and pathogenesis. Respiration 2003;70:730 .

5. Winters B, Custer J, Galvagno SM, Jr., Colantuoni E, Kapoor SG, Lee H, Goode V, Robinson K, Nakhasi A, Pronovost P, Newman-Toker D. Diagnostic errors in the intensive care unit: a systematic review of autopsy studies. BMJ quality \& safety 2012;21:894-902.

6. Cook D, Meade M, Guyatt G, Griffith L, Granton J, Geerts W, Crowther M; Canadian Critical Care Trials Group. Clinically important deep vein thrombosis in the intensive care unit: a survey of intensivists. Crit Care 2004; 8:145-52.

7. Guyatt GH, Akl EA, Crowther M, Gutterman DD, Schuunemann HJ. Executive summary: Antithrombotic Therapy and Prevention of Thrombosis, 9th ed: American College of Chest Physicians Evidence-Based Clinical Practice Guidelines. Chest 2012; 141:Suppl 1:7-47.

8. Ho KM, Chavan S, Pilcher D. Omission of early thromboprophylaxis and mortality in critically ill patients: a multicenter registry study. Chest 2011;140:1436-46.

9. Hirsch DR, Ingenito EP, Goldhaber SZ. Prevalence of deep venous thrombosis among patients in medical intensive care. Jama 1995;274:335-7.

10. Lamontagne F, McIntyre L, Dodek P, Heels-Ansdell D, Meade M, Pemberton J, Skrobik Y, Seppelt I, Vlahakis NE, Muscedere J, Reece G, Ostermann M, Padayachee S, Alhashemi J, Walsh M, Lewis B, Schiff D, Moody A, Zytaruk N, Leblanc M, Cook DJ; Prophylaxis for Thromboembolism in Critical Care Trial Investigators; Canadian Critical Care Trials Group; Australian and New Zealand Intensive Care Society Clinical Trials Group. Nonleg venous thrombosis in critically ill adults: a nested prospective cohort study. JAMA internal medicine 2014; 174:689-96.

11. Hrdy O, Strazevska E, Suk P, Vach R, Karlik R, Jarkovsky J, Sas I, Gal R. Central venous catheter-related thrombosis in intensive care patients - incidence and risk factors: A prospective observational study. Biomedical papers of the Medical Faculty of the University Palacky, Olomouc, Czechoslovakia 2017. E-published ahead of print.

12. Joynt GM, Kew J, Gomersall CD, Leung VY, Liu EK. Deep venous thrombosis caused by femoral venous catheters in critically ill adult patients. Chest 2000; 117:178-83.

13. Hirsch DR, Ingenito EP, Goldhaber SZ. Prevalence of deep venous thrombosis among patients in medical intensive care. JAMA 1995; 274:335-7. 
14. Marik PE, Andrews L, Maini B. The incidence of deep venous thrombosis in ICU patients. Chest 1997;111:661-4.

15. Twigg SJ, McCrirrick A, Sanderson PM. A comparison of post mortem findings with post hoc estimated clinical diagnoses of patients who die in a United Kingdom intensive care unit. Intensive Care Med 2001;27:706-10.

16. Charlson ME, Pompei P, Ales KL, MacKenzie CR. A new method of classifying prognostic comorbidity in longitudinal studies: development and validation. J Chronic Dis 1987;40:373-83.

17. Le Gall JR, Lemeshow S, Saulnier F. A new Simplified Acute Physiology Score (SAPS II) based on a European/North American multicenter study. JAMA 1993;270:2957-63.

18. Vincent JL, de Mendonca A, Cantraine F, Moreno R, Takala J, Suter PM, Sprung CL, Colardyn F, Blecher S. Use of the SOFA score to assess the incidence of organ dysfunction/failure in intensive care units: results of a multicenter, prospective study. Working group on "sepsis-related problems" of the European Society of Intensive Care Medicine. Crit Care Med 1998;26:1793-1800.

19. Kidney Disease: Improving Global Outcomes (KDIGO) Acute Kidney Injury Work Group. KDIGO clinical practice guideline for acute kidney injury. Kidney Int Suppl. 2013;2:1-138.

20. Kory PD, Pellecchia CM, Shiloh AL, Mayo PH, DiBello C, Koenig S. Accuracy of ultrasonography performed by critical care physicians for the diagnosis of DVT. Chest 2011;139:538-42.

21. Remy-Jardin M, Pistolesi M, Goodman LR, Gefter WB, Gottschalk A, Mayo JR, Sostman HD. Management of suspected acute pulmonary embolism in the era of CT angiography: a statement from the Fleischner Society. Radiology 2007;245:315-29.

22. Geerts WH, Pineo GF, Heit JA, Bergqvist D, Lassen MR, Colwell CW, Ray JG. Prevention of venous thromboembolism: the Seventh ACCP Conference on Antithrombotic and Thrombolytic Therapy. Chest 2004;126: Suppl 1:338-400.

23. Ribic C, Lim W, Cook D, Crowther M. Low-molecular-weight heparin thromboprophylaxis in medical-surgical critically ill patients: a systematic review. $\mathrm{J}$ Crit Care 2009;24:197-205.

24. Beitland S, Sandven I, Kjaervik LK, Sandset PM, Sunde K, Eken T: Thromboprophylaxis with low molecular weight heparin versus unfractionated heparin in intensive care patients: a systematic review with meta-analysis and trial sequential analysis. Intensive Care Med 2015;41:1209-19.

25. Combes A, Mokhtari M, Couvelard A, Trouillet JL, Baudot J, Henin D, Gibert C, Chastre J. Clinical and autopsy diagnoses in the intensive care unit: a prospective study. Arch Intern Med 2004;164:389-92.

26. Pannucci CJ, Obi A, Alvarez R, Abdullah N, Nackashi A, Hu HM, Bahl V, Henke PK. Inadequate venous thromboembolism risk stratification predicts venous thromboembolic events in surgical intensive care unit patients. J Am Coll Surg 2014; 218:898-904.

27. Lim W, Dentali F, Eikelboom JW, Crowther MA. Meta-analysis: low-molecularweight heparin and bleeding in patients with severe renal insufficiency. Ann Intern Med 2006;144:673-84.

28. Rabbat CG, Cook DJ, Crowther MA, McDonald E, Clarke F, Meade MO, Lee KA, Cook RJ. Dalteparin thromboprophylaxis for critically ill medical-surgical patients with renal insufficiency. J Crit Care 2005;20:357-63. 
29. Cook D, Meade M, Guyatt G, Walter S, Heels-Ansdell D, Warkentin TE, Zytaruk N, Crowther M, Geerts W, Cooper DJ, Vallance S, Qushmaq I, Rocha M, Berwanger O, Vlahakis NE. Dalteparin versus unfractionated heparin in critically ill patients. N Engl J Med 2011;3644:1305-14.

30. Malato A, Dentali F, Siragusa S, Fabbiano F, Kagoma Y, Boddi M, Gensini GF, Peris A, Crowther M, Napolitano M. The impact of deep vein thrombosis in critically ill patients: a meta-analysis of major clinical outcomes. Blood Transfus 2015;13:559-68.

31. Monreal M, Raventos A, Lerma R, Ruiz J, Lafoz E, Alastrue A, Llamazares JF. Pulmonary embolism in patients with upper extremity DVT associated to venous central lines--a prospective study. Thromb Haemost 1994, 72;4:548-50.

32. Kooij JD, van der Zant FM, van Beek EJ, Reekers JA. Pulmonary embolism in deep venous thrombosis of the upper extremity: more often in catheter-related thrombosis. Neth J Med 1997;50:238-42.

33. Cook D, Attia J, Weaver B, McDonald E, Meade M, Crowther M. Venous thromboembolic disease: an observational study in medical-surgical intensive care unit patients. J Crit Care 2000;15:127-32.

34. Merrer J, De Jonghe B, Golliot F, Lefrant JY, Raffy B, Barre E, Rigaud JP, Casciani D, Misset B, Bosquet C, Outin H, Brun-Buisson C, Nitenberg G; French Catheter Study Group in Intensive Care. Complications of femoral and subclavian venous catheterization in critically ill patients: a randomized controlled trial. JAMA 2001; 286:700-7.

35. Ascher E, Salles-Cunha S, Hingorani A. Morbidity and mortality associated with internal jugular vein thromboses. Vasc Endovascular Surg 2005;39:335-9.

36. Harris LM, Curl GR, Booth FV, Hassett JM, Jr., Leney G, Ricotta JJ. Screening for asymptomatic deep vein thrombosis in surgical intensive care patients. J Vasc Surg 1997;26:764-9.

37. Schultz DJ, Brasel KJ, Washington L, Goodman LR, Quickel RR, Lipchik RJ, Clever $\mathrm{T}$, Weigelt $\mathrm{J}$. Incidence of asymptomatic pulmonary embolism in moderately to severely injured trauma patients. J Trauma 2004;56:727-31.

38. Minet C, Lugosi M, Savoye PY, Menez C, Ruckly S, Bonadona A, Schwebel C, Hamidfar-Roy R, Dumanoir P, Ara-Somohano C, Ferretti GR, Timsit JF. Pulmonary embolism in mechanically ventilated patients requiring computed tomography: Prevalence, risk factors, and outcome. Crit Care Med 2012;40:3202-3208.

39. Goldhaber SZ, Visani L, De Rosa M. Acute pulmonary embolism: clinical outcomes in the International Cooperative Pulmonary Embolism Registry (ICOPER). Lancet 1999;353:1386-9.

40. Torbicki A, Perrier A, Konstantinides S, Agnelli G, Galie N, Pruszczyk P, Bengel F, Brady AJ, Ferreira D, Janssens U, Klepetko W, Mayer E, Remy-Jardin M, Bassand JP; ESC Committee for Practice Guidelines (CPG). Guidelines on the diagnosis and management of acute pulmonary embolism: the Task Force for the Diagnosis and Management of Acute Pulmonary Embolism of the European Society of Cardiology (ESC). Eur Heart J 2008;29:2276-315.

41. Long B, Koyfman A. Best Clinical Practice: Current Controversies in Pulmonary Embolism Imaging and Treatment of Subsegmental Thromboembolic Disease. J Emerg Med 2017; 52:184-93. 
Analysis

\section{Follow-Up}

\section{Enrollment}

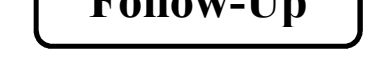

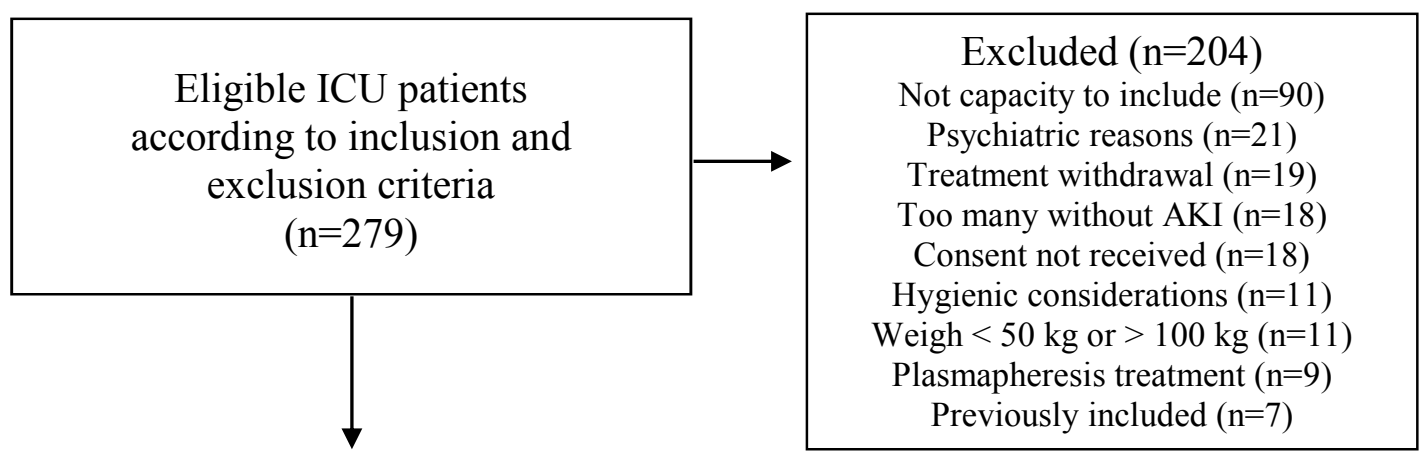

Patients receiving prophylactic dalteparin with anticipated ICU LOS $>48$ hours $(n=75)$

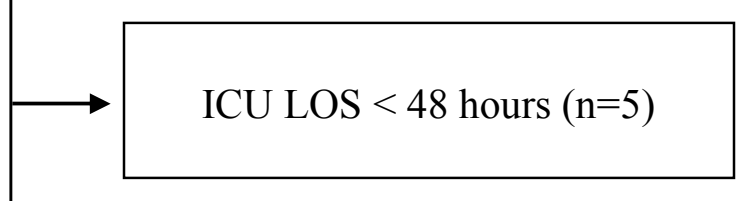

Patients receiving prophylactic dalteparin with actual

ICU LOS $>48$ hours

$$
(n=70)
$$


Model I

Parameters included

Malignancy

SAPS II score $>41$

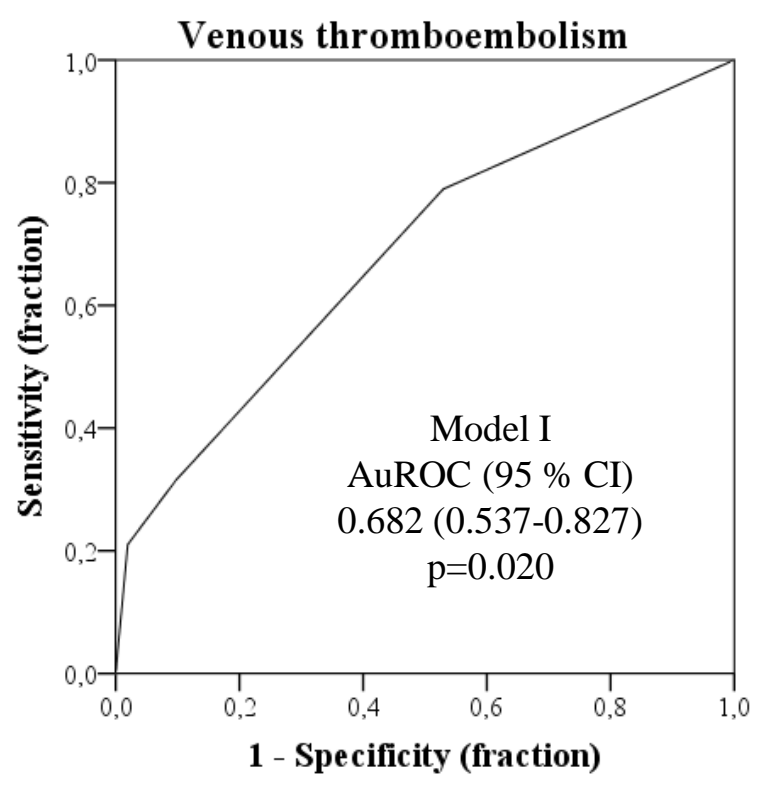

Model II

Parameters included

Malignancy

Abdominal surgery

SAPS II score > 41

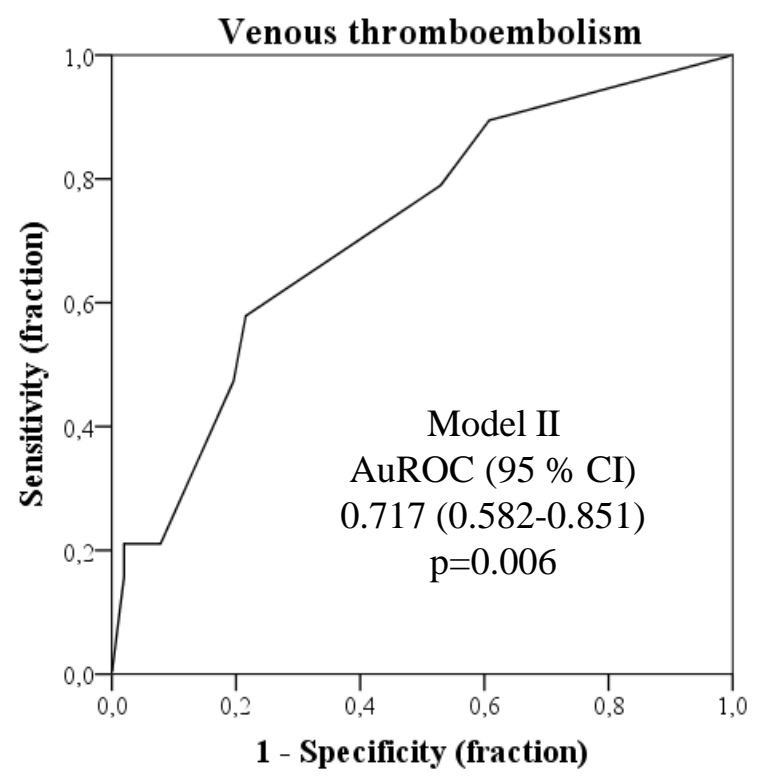




\section{Observed venous thromboembolism $(\mathbf{n}=19)$}

Located as internal jugular vein thrombosis $(n=9)$, pulmonary embolism $(n=4)$ or thrombosis of the brachial $(n=2)$, inferior mesenteric $(n=1)$, external iliacal $(n=1)$, femoral $(n=1)$ or bilateral popliteal $(n=1)$ veins
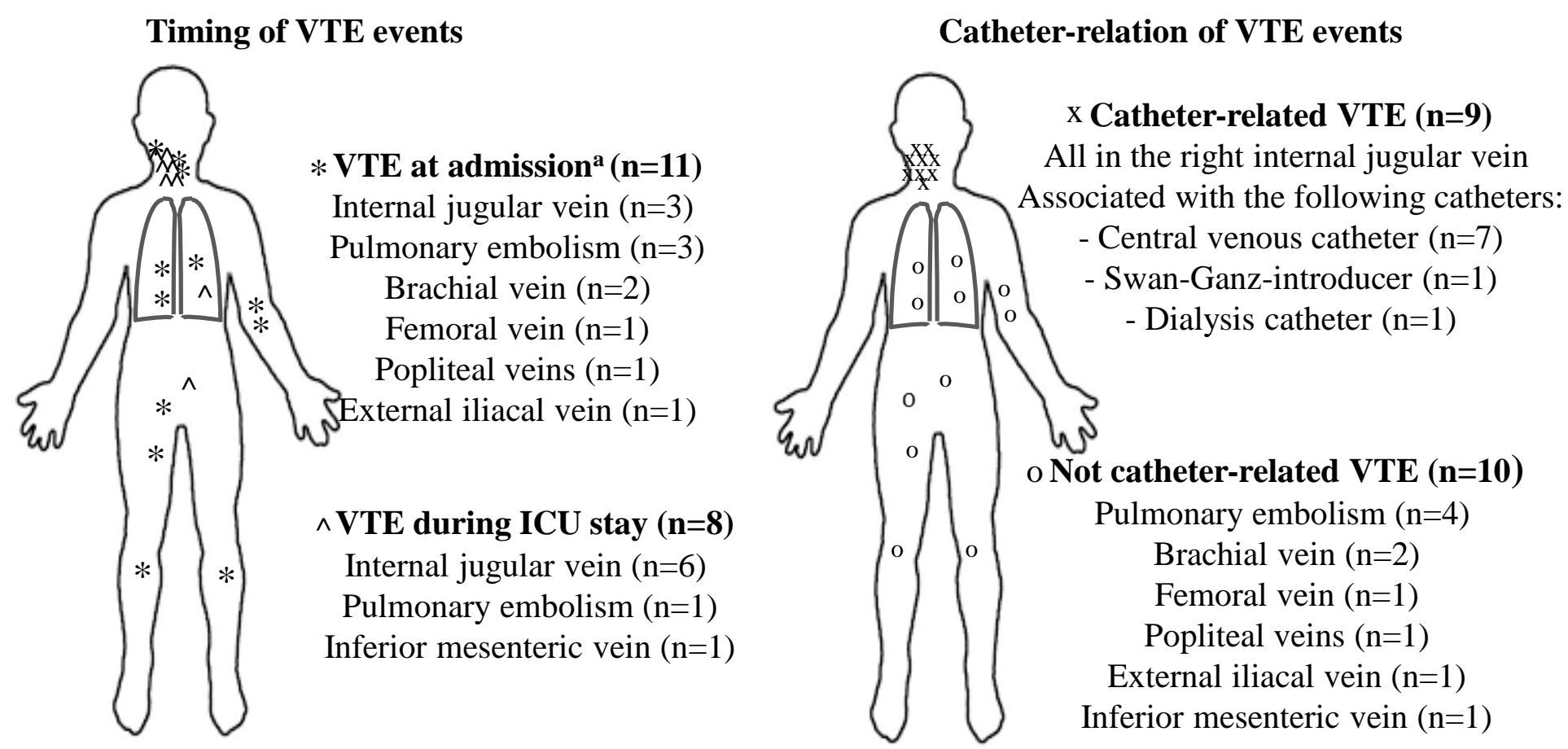
Table 1 Univariate analyses of risk factors for venous thromboembolism

\begin{tabular}{|c|c|c|c|c|c|}
\hline Baseline data & $\begin{array}{c}\text { Patients } \\
\text { with VTE } \\
(n=19) \\
\end{array}$ & $\begin{array}{c}\text { Patients } \\
\text { without VTE } \\
(n=51)\end{array}$ & 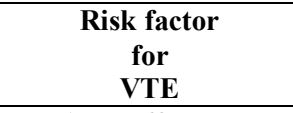 & $\begin{array}{c}\text { Crude OR } \\
(95 \% \text { CI) } \\
\text { for VTE } \\
\end{array}$ & $\begin{array}{c}p- \\
\text { value }\end{array}$ \\
\hline Age, years & $63.0 \pm 12.2$ & $60.9 \pm 12.2$ & Age $>63$ years & $0.94(0.33-2.69)$ & 0.902 \\
\hline Male sex & $16(84.2)$ & $39(76.5)$ & Male sex & $1.64(0.41-6.61)$ & 0.744 \\
\hline Weight, kilogram & $84.0(78.0-90.0)$ & $80.0(70.0-90.0)$ & Weight $>82 \mathrm{~kg}$ & $1.47(0.51-4.22)$ & 0.478 \\
\hline BMI, kilogram $/$ meter $^{2}$ & $24.5(22.6-26.0)$ & $24.8(22.6-26.7)$ & $\mathrm{BMI}>25 \mathrm{~kg} / \mathrm{m}^{2}$ & $0.61(0.20-1.86)$ & 0.380 \\
\hline Surgical admission & $12(63.2)$ & $38(74.5)$ & Surgical admission & $0.59(0.19-1.81)$ & 0.350 \\
\hline Any comorbidity & $12(63.2)$ & $36(70.6)$ & Comorbidity & $0.71(0.24-2.17)$ & 0.552 \\
\hline \multicolumn{6}{|l|}{ Patient risk factors } \\
\hline Neurosurgery last 6 weeks & $0(0.0)$ & $5(9.8)$ & Neurosurgery & $0.71(0.61-0.83)$ & 0.313 \\
\hline Thoracic surgery last 6 weeks & $2(10.5)$ & $4(7.8)$ & Thoracic surgery & $1.38(0.23-8.24)$ & 0.660 \\
\hline Abdominal surgery last 6 weeks & $10(52.6)$ & $14(27.5)$ & Abdominal surgery & $2.94(0.99-8.74)$ & 0.048 \\
\hline Orthopaedic surgery last 6 weeks & $1(5.3)$ & $4(7.8)$ & Orthopaedic surgery & $0.65(0.07-6.24)$ & 1.000 \\
\hline Trauma last 6 weeks & $0(0.0)$ & $7(13.7)$ & Trauma & $0.70(0.59-0.82)$ & 0.177 \\
\hline Immobilisation & $19(100.0)$ & $50(98.0)$ & Immobilisation & $1.38(1.19-1.60)$ & 1.000 \\
\hline Paresis of lower extremities & $1(5.3)$ & $2(3.9)$ & Paresis & $1.36(0.12-15.9)$ & 1.000 \\
\hline Malignancy, any type & $6(31.6)$ & $5(9.8)$ & Malignancy & $4.25(1.12-16.2)$ & 0.058 \\
\hline Venous compression & $1(5.3)$ & $3(5.9)$ & Venous compression & $0.89(0.09-9.11)$ & 1.000 \\
\hline Previous VTE & $2(10.5)$ & $0(0.0)$ & Previous VTE & $4.00(2.65-6.04)$ & 0.071 \\
\hline First degree relative with VTE & $0(0.0)$ & $0(0.0)$ & Relative with VTE & n.a. & n.a. \\
\hline Other risk factor ${ }^{\mathrm{a}}$ & $0(0.0)$ & $0(0.0)$ & Other risk factor ${ }^{\mathrm{a}}$ & n.a. & n.a. \\
\hline \multicolumn{6}{|l|}{ ICU risk factors } \\
\hline Catheter femoral vein $(n=59)^{b}$ & $2(25.0)$ & $15(29.4)$ & Femoral catheter $^{b}$ & $0.80(0.15-4.42)$ & 1.000 \\
\hline Catheter subclavian vein $(n=59)^{b}$ & $5(62.5)$ & $33(64.7)$ & Subclavian catheter ${ }^{\mathrm{b}}$ & $0.91(0.19-4.25)$ & 1.000 \\
\hline Catheter IJV $(\mathrm{n}=59)^{\mathrm{b}}$ & $8(100.0)$ & $33(67.4)$ & IJV catheter $^{\mathrm{b}}$ & $1.24(1.07-1.45)$ & 0.092 \\
\hline SOFA score admission day & $8.5(3.8-16.8)$ & $8.0(6.0-11.0)$ & SOFA score $>8$ & $0.60(0.19-1.94)$ & 0.391 \\
\hline SAPS II, score & $36.4 \pm 14.4$ & $41.9 \pm 16.6$ & SAPS II score $>41$ & $0.38(0.13-1.15)$ & 0.083 \\
\hline Presence of severe AKI & $9(47.4)$ & $26(51.0)$ & Severe AKI & $0.87(0.30-2.49)$ & 0.788 \\
\hline Low-dose dalteparin $(n=59)^{b, c}$ & $2(25.0)$ & $13(25.5)$ & Low-dose dalteparin ${ }^{\mathrm{b}, \mathrm{c}}$ & $0.97(0.18-5.44)$ & 1.000 \\
\hline Low-dose GCS $(n=59)^{b, d}$ & $3(37.5)$ & $19(37.3)$ & Low-dose GCS ${ }^{\text {b,d }}$ & $1.01(0.22-4.71)$ & 1.000 \\
\hline Number of DUS examinations & $3.5(2.0-4.8)$ & $2.0(2.0-5.0)$ & DUS examinations $>3$ & $0.58(0.17-2.04)$ & 0.395 \\
\hline \multicolumn{6}{|l|}{ Outcome } \\
\hline ICU LOS & $13.0(5.0-21.0)$ & $11.0(7.0-16.0)$ & ICU LOS $>16$ days & $1.90(0.61-5.90)$ & 0.265 \\
\hline Hospital LOS & $19.0(13.0-30.0)$ & $18.0(10.0-30.0)$ & Hospital LOS $>23$ days & $1.07(0.36-3.20)$ & 0.904 \\
\hline ICU mortality & $3(15.8)$ & $10(19.6)$ & Dead in ICU & $0.77(0.19-3.16)$ & 0.715 \\
\hline Hospital mortality & $3(15.8)$ & $12(23.5)$ & Dead in hospital & $0.61(0.15-2.45)$ & 0.744 \\
\hline Mortality 1 year & $5(26.3)$ & $19(37.3)$ & Dead within 1 year & $0.60(0.19-1.94)$ & 0.391 \\
\hline \multicolumn{6}{|c|}{$\begin{array}{l}\text { Categorical data are presented as number (\%) and compared using two-sided Pearson's Chi square test, and Fisher's exact test when } \\
\text { appropriate. Continuous data with skewed distribution are presented as median (interquartile range), and continuous data with normal } \\
\text { distribution are presented as mean ( } \pm \text { standard deviation). VTE venous thromboembolism, OR odds ratio, } C I \text { confidence interval, } B M I \text { body } \\
\text { mass index, ICU intensive care unit, } I J V \text { internal jugular vein, SOFA sequential organ failure assessment, SAPS simplified acute physiology } \\
\text { score, } A K I \text { acute kidney injury, GCS graduated compression stockings, DUS Doppler ultrasound, } L O S \text { length of stay, n.a. not applicable. } \\
\text { a Other risk factors assessed were presence of oestrogen hormone treatment, inflammatory bowel disease, nephrotic syndrome, } \\
\text { myeloproliferative disorders and paroxysmal nocturnal haemoglobinuria. }{ }^{b} \text { Only assessed in patients without VTE at admission. }{ }^{c} \text { Low-dose } \\
\text { dalteparin was defined as mean dalteparin }<5000 \text { IE/day. }{ }^{d} \text { Low-dose GCS was defined as use of bilateral graduated compression stockings } \\
<20 \text { hours/day. }\end{array}$} \\
\hline
\end{tabular}


Table 2 Multivariate analyses of risk factors for venous thromboembolism

\begin{tabular}{|c|c|c|c|c|c|c|c|}
\hline \multirow{4}{*}{ Model I } & \multirow[b]{2}{*}{ Variables } & \multicolumn{3}{|c|}{ Univariate } & \multicolumn{3}{|c|}{ Multivariate } \\
\hline & & OR & $95 \%$ CI & p-value & OR & $95 \%$ CI & p-value \\
\hline & Malignancy & 4.25 & $1.12-16.2$ & 0.058 & 5,13 & $1,24-21.27$ & 0.024 \\
\hline & SAPS II score $>41$ & 0.38 & $0.13-1.15$ & 0.083 & 0.32 & $0.01-1.05$ & 0.061 \\
\hline \multirow{3}{*}{ Model II } & Malignancy & 4.25 & $1.12-16.2$ & 0.058 & 4.12 & $0.94-18.08$ & 0.061 \\
\hline & Abdominal surgery & 2.94 & $0.99-8.74$ & 0.048 & 1.98 & $0.61-6.47$ & 0.256 \\
\hline & SAPS II score $>41$ & 0.38 & $0.13-1.15$ & 0.083 & 0.36 & $0.11-1.19$ & 0.094 \\
\hline
\end{tabular}

OR odds ratio, $C I$ confidence interval, SAPS simplified acute physiology score. 


\section{Figure legends}

\section{Figure 1}

Title: Flow chart of the study.

Legend: $I C U$ intensive care unit, $L O S$ length of stay, $A K I$ acute kidney injury, $k g$ kilogram.

\section{Figure 2}

Title: Predictive models for venous thromboembolism.

Legend: Data presented as area under receiver operating characteristics curve $(A u R O C)$ with odds ratio $(O R)$ and $95 \%$ confidence interval $(C I), S A P S$ simplified acute physiology score.

\section{Figure 3}

Title: Venous thromboembolism events observed in the study.

Legend: VTE venous thromboembolism, $I C U$ intensive care unit. ${ }^{\text {a}} \mathrm{VTE}$ present at admission was defined as DVT and PE diagnosed within 48 hours after ICU admission. 


\section{Appendix S1 Comparison of VTE related to intravenous catheters and not}

\begin{tabular}{|c|c|c|c|c|}
\hline Baseline data & $\begin{array}{c}\text { All } \\
\text { VTE } \\
(n=19)\end{array}$ & $\begin{array}{c}\text { Catheter- } \\
\text { related VTE } \\
(n=9)\end{array}$ & $\begin{array}{l}\text { Not catheter- } \\
\text { related VTE } \\
\quad(n=10)\end{array}$ & $\begin{array}{c}\text { p- } \\
\text { value }\end{array}$ \\
\hline Age, years & $63.0 \pm 12.2$ & $61.0 \pm 12.8$ & $64.0 \pm 12.2$ & 0.717 \\
\hline Male sex & $16(84.2)$ & $8(88.9)$ & $8(80.0)$ & 1.000 \\
\hline Surgical admission & $12(63.2)$ & $6(66.7)$ & $6(60.0)$ & 1.000 \\
\hline Any comorbidity & $12(63.2)$ & $6(66.7)$ & $6(60.0)$ & 1.000 \\
\hline SAPS II, score & $36.4 \pm 14.4$ & $36.4 \pm 17.4$ & $36.3 \pm 12.1$ & 0.983 \\
\hline \multicolumn{5}{|l|}{ Patient risk factors } \\
\hline Surgery or trauma last 6 weeks & $11(57.9)$ & $5(55.6)$ & $6(60.0)$ & 1.000 \\
\hline Immobilisation & $19(100.0)$ & $9(100.0)$ & $10(100.0)$ & n.a. \\
\hline Paresis of lower extremities & $1(5.3)$ & $0(0)$ & $1(10.0)$ & 1.000 \\
\hline Cancer, any type & $6(31.6)$ & $3833.3)$ & $3(30.0)$ & 1.000 \\
\hline Venous compression & $1(5.3)$ & $0(0.0)$ & $1(10.0)$ & 1.000 \\
\hline Previous VTE & $2(10.5)$ & $1(11.1)$ & $1(10.0)$ & 1.000 \\
\hline \multicolumn{5}{|l|}{ ICU risk factors ${ }^{a}(n=8)$} \\
\hline CVC catheter femoral vein & $1(12,5)$ & $1(16.7)$ & $0(0.0)$ & 1.000 \\
\hline CVC catheter subclavian vein & $4(50.0)$ & $3(50.0)$ & $1(50.0)$ & 1.000 \\
\hline CVC catheter internal jugular vein & $8(100.0)$ & $6(100.0)$ & $2(100.0)$ & n.a. \\
\hline Dialysis catheter femoral vein & $2(25.0)$ & $2(33.0)$ & $0(0.0)$ & 1.000 \\
\hline Dialysis catheter subclavian vein & $2(25.0)$ & $2(33.0)$ & $0(0.0)$ & 1.000 \\
\hline Dialysis catheter internal jugular vein & $2(25.0)$ & $1(16.7)$ & $1(50.0)$ & 0.464 \\
\hline Low-dose dalteparin ${ }^{b}$ & $2(25.0)$ & $2(33.0)$ & $0(0.0)$ & 1.000 \\
\hline Low-dose GCS & $3(37.5)$ & $3(50.0)$ & $0(0.0)$ & 0.464 \\
\hline \multicolumn{5}{|l|}{ VTE characteristics } \\
\hline Time to VTE, days & $2.0(1.0-9.0)$ & $5.0(1.5-14.0)$ & $1.0(1.0-3.5)$ & 0.034 \\
\hline DVT in femoral vein & $1(5.3)$ & $0(0.0)$ & $1(10.0)$ & 1.000 \\
\hline DVT in subclavian vein & $0(0.0)$ & $0(0.0)$ & $0(0.0)$ & n.a. \\
\hline DVT in internal jugular vein & $9(47.4)$ & $9(100.0)$ & $0(0.0)$ & $<0.001$ \\
\hline DVT in other vein & $5(26.3)$ & $0(0.0)$ & $5(50.0)$ & 0.033 \\
\hline $\mathrm{PE}$ & $4(21.1)$ & $0(0)$ & $4(40.0)$ & 0.087 \\
\hline Diagnosed by DUS screening & $11(57.9)$ & $8(88.9)$ & $3(30.0)$ & 0.020 \\
\hline Symptomatic & $5(26.3)$ & $0(0.0)$ & $5(50.0)$ & 0.033 \\
\hline Treated with anticoagulation & $15(78.9)$ & $6(66.7)$ & $9(90.0)$ & 0.303 \\
\hline $\begin{array}{l}\text { Treated with removal of the catheter } \\
\text { Outcome }\end{array}$ & \multicolumn{3}{|c|}{ Outcome } & 0.001 \\
\hline ICU LOS & $13.0(5.0-21.0)$ & $13.0(8.0-38.5)$ & $8.5(4.5-19.0)$ & 0.182 \\
\hline Hospital LOS & $19.0(13.0-30.0)$ & $26.0(13.0-54.0)$ & $18.0(7.3-21.3)$ & 0.053 \\
\hline ICU and hospital mortality & $3(15.8)$ & $0(0)$ & $3(30.0)$ & 0.211 \\
\hline Mortality 1 year & $5(26.3)$ & $1(11.1)$ & $4(40.0)$ & 0.303 \\
\hline \multicolumn{5}{|c|}{$\begin{array}{l}\text { Categorical data are presented as number (\%) and compared using two-sided Pearson's Chi square test, and Fisher's exact test when } \\
\text { appropriate. Continuous data had skewed distribution and are presented as median (interquartile range), and compared using two-tailed } \\
\text { Mann-Whitney U test. Continuous data with normal distribution are presented as mean ( } \pm \text { standard deviation), and compared using two- } \\
\text { sided independent sample T test. VTE venous thromboembolism, } S A P S \text { simplified acute physiology score, } I C U \text { intensive care unit, } \\
C V C \text { central venous catheter, GCS graduated compression stockings, } D V T \text { deep vein thrombosis, } P E \text { pulmonary embolism, } \\
D U S \text { Doppler ultrasound, } L O S \text { length of stay, n.a. not applicable. }{ }^{\text {a }} \text { Treatment risk factors were only assessed in patients without VTE at } \\
\text { admission. b Low-dose dalteparin was defined as mean dalteparin }<5000 \mathrm{IU} / \text { day. }{ }^{c} \text { Low-dose GCS was defined as use of graduated } \\
\text { compression stockings bilateral to knee or hip level< mean } 20 \text { hours/day. }\end{array}$} \\
\hline
\end{tabular}


Appendix S2 Comparison of symptomatic and asymptomatic VTE

\begin{tabular}{|c|c|c|c|c|}
\hline Baseline data & $\begin{array}{c}\text { All } \\
\text { VTE } \\
(n=19)\end{array}$ & $\begin{array}{c}\text { Symptomatic } \\
\text { VTE } \\
(\mathrm{n}=5) \\
\end{array}$ & $\begin{array}{c}\text { Asymptomatic } \\
\text { VTE } \\
(\mathrm{n}=14) \\
\end{array}$ & $\begin{array}{c}\text { p- } \\
\text { value }\end{array}$ \\
\hline Age, years & $63.0 \pm 12.2$ & $67.0 \pm 7.8$ & $61.6 \pm 13.4$ & 0.408 \\
\hline Male sex & $16(84.2)$ & $4(80.0)$ & $12885.7)$ & 1.000 \\
\hline Surgical admission & $12(63.2)$ & $3(60.0)$ & $9(64.3)$ & 1.000 \\
\hline Any comorbidity & $12(63.2)$ & $3(60.0)$ & $9(64.3)$ & 1.000 \\
\hline SAPS II, score & $36.4 \pm 14.4$ & $29.4 \pm 7.5$ & $38.9 \pm 15.6$ & 0.216 \\
\hline \multicolumn{5}{|l|}{ Patient risk factors } \\
\hline Surgery or trauma last 6 weeks & $11(57.9)$ & $3(60.0)$ & $8(57.1)$ & 1.000 \\
\hline Immobilisation & $19(100.0)$ & $5(100.0)$ & $14(100.0)$ & n.a. \\
\hline Paresis of lower extremities & $1(5.3)$ & $0(0.0)$ & $1(7.1)$ & 1.000 \\
\hline Cancer, any type & $6(31.6)$ & $2(40.0)$ & $4(28.6)$ & 1.000 \\
\hline Venous compression & $1(5.3)$ & $1(20.0)$ & $0(0.0)$ & 0.263 \\
\hline Previous VTE & $2(10.5)$ & $1(20.0)$ & $1 / 7.1)$ & 0.468 \\
\hline \multicolumn{5}{|l|}{ ICU risk factors $^{\mathrm{a}}(\mathrm{n}=8)$} \\
\hline CVC catheter femoral vein & $1(12,5)$ & $0(0.0)$ & $1(14.3)$ & 1.000 \\
\hline CVC catheter subclavian vein & $4(50.0)$ & $0(0.0)$ & $4(57.1)$ & 1.000 \\
\hline CVC catheter internal jugular vein & $8(100.0)$ & $1(100.0)$ & $7(100.0)$ & n.a. \\
\hline Dialysis catheter femoral vein & $2(25.0)$ & $0(0.0)$ & $2(28.6)$ & 1.000 \\
\hline Dialysis catheter subclavian vein & $2(25.0)$ & $0(0.0)$ & $2(28.6)$ & 1.000 \\
\hline Dialysis catheter internal jugular vein & $2(25.0)$ & $0(0.0)$ & $2(28.6)$ & 1.000 \\
\hline Low-dose dalteparin ${ }^{\mathrm{b}}$ & $2(25.0)$ & $0(0.0)$ & $2(28.6)$ & 1.000 \\
\hline Low-dose GCS & $3(37.5)$ & $0(0.0)$ & $3(37.5)$ & 1.000 \\
\hline \multicolumn{5}{|l|}{ VTE characteristics } \\
\hline Time to VTE, days & $2.0(1.0-9.0)$ & $1(1.0-4.5)$ & $2.5(1.0-12.5)$ & 0.156 \\
\hline DVT in femoral vein & $1(5.3)$ & $0(0.0)$ & $1(7.1)$ & 1.000 \\
\hline DVT in subclavian vein & $0(0.0)$ & $0(0.0)$ & $0(0.0)$ & n.a. \\
\hline DVT in internal jugular vein & $9(47.4)$ & $0(0.0)$ & $9(64.3)$ & 0.033 \\
\hline DVT in other vein & $5(26.3)$ & $2(40.0)$ & $3(21.4)$ & 0.570 \\
\hline $\mathrm{PE}$ & $4(21.1)$ & $3(60.0)$ & $1(7.1)$ & 0.037 \\
\hline Diagnosed by DUS screening & $11(57.9)$ & $1(20.0)$ & $10(71.4)$ & 0.111 \\
\hline Catheter related VTE & $9(47.4)$ & $0(0.0)$ & $9(64.3)$ & 0.033 \\
\hline Treated with anticoagulation & $15(78.9)$ & $4(80.0)$ & $11(78.6)$ & 1.000 \\
\hline Treated with removal of the catheter & $7(36.8)$ & $0(0.0)$ & $7(50.0)$ & 0.106 \\
\hline \multicolumn{5}{|l|}{ Outcome } \\
\hline ICU LOS & $13.0(5.0-21.0)$ & $16.0(7.0-19.0)$ & $12.0(4.5-25.8)$ & 0.889 \\
\hline Hospital LOS & $19.0(13.0-30.0)$ & $19.0(9.0-20.5)$ & $22.5(13.0-35.8)$ & 0.285 \\
\hline ICU and hospital mortality & $3(15.8)$ & $2(40.0)$ & $1(7.1)$ & 0.155 \\
\hline Mortality 1 year & $5(26.3)$ & $2(40.0)$ & $3(21.4)$ & 0.570 \\
\hline \multicolumn{5}{|c|}{$\begin{array}{l}\text { Categorical data are presented as number (\%) and compared using two-sided Pearson's Chi square test, and Fisher's exact test when } \\
\text { appropriate. Continuous data had skewed distribution and are presented as median (interquartile range), and compared using two-tailed } \\
\text { Mann-Whitney U test. Continuous data with normal distribution are presented as mean ( } \pm \text { standard deviation), and compared using two- } \\
\text { sided independent sample T test. VTE venous thromboembolism, SAPS simplified acute physiology score, ICU intensive care unit, } \\
C V C \text { : central venous catheter, } D V T \text { deep vein thrombosis, } P E \text { pulmonary embolism, DUS Doppler ultrasound, } L O S \text { length of stay, } \\
\text { n.a. not applicable. }{ }^{\text {a } T r e a t m e n t ~ r i s k ~ f a c t o r s ~ w e r e ~ o n l y ~ a s s e s s e d ~ i n ~ p a t i e n t s ~ w i t h o u t ~ V T E ~ a t ~ a d m i s s i o n . ~}{ }^{b} \text { Low-dose dalteparin was defined as } \\
\text { mean dalteparin }<5000 \mathrm{IU} / \text { day. }{ }^{\mathrm{c}} \text { Low-dose GCS was defined as use of graduated compression stockings bilateral to knee or hip } \\
\text { level<mean } 20 \text { hours/day. }\end{array}$} \\
\hline
\end{tabular}




\section{Appendix S3 Comparison of VTE present at admission a and developing during ICU stay}

\begin{tabular}{|c|c|c|c|c|}
\hline Baseline data & $\begin{array}{c}\text { All } \\
\text { VTE } \\
(n=19) \\
\end{array}$ & $\begin{array}{c}\text { VTE at } \\
\text { admission }^{a} \\
(n=11)\end{array}$ & $\begin{array}{c}\text { VTE during } \\
\text { ICU stay } \\
(n=8)\end{array}$ & $\begin{array}{c}\text { p- } \\
\text { value }\end{array}$ \\
\hline Age, years & $63.0 \pm 12.2$ & $62.7 \pm 11.8$ & $63.4 \pm 13.5$ & 0.913 \\
\hline Male sex & $16(84.2)$ & $9(81.8)$ & $7(87.5)$ & 1.000 \\
\hline Surgical admission & $12(63.2)$ & $6(54.5)$ & $6(75.0)$ & 0.633 \\
\hline Any comorbidity & $12(63.2)$ & $7(63.6)$ & $5(62.5)$ & 1.000 \\
\hline SAPS II, score & $36.4 \pm 14.4$ & $33.9 \pm 13.2$ & $39.8 \pm 16.1$ & 0.398 \\
\hline \multicolumn{5}{|l|}{ Patient risk factors } \\
\hline Surgery or trauma last 6 weeks & $11(57.9)$ & $6(54.4)$ & $5(62.5)$ & 1.000 \\
\hline Immobilisation & $19(100.0)$ & $11(100.0)$ & $8(100.0)$ & n.a. \\
\hline Paresis of lower extremities & $1(5.3)$ & $1(9.1)$ & $0(0.0)$ & 1.000 \\
\hline Cancer, any type & $6(31.6)$ & $4(36.4)$ & $2(25.0)$ & 1.000 \\
\hline Venous compression & $1(5.3)$ & $1(9.1)$ & $0(0.0)$ & 1.000 \\
\hline Previous VTE & $2(10.5)$ & $1(9.1)$ & $1(12.5)$ & 1.000 \\
\hline \multicolumn{5}{|l|}{ VTE characteristics } \\
\hline Time to VTE, days & $2.0(1.0-9.0)$ & $1.0(1.0-1.0)$ & $10.5(5.8-14.0)$ & $<0.001$ \\
\hline DVT in femoral vein & $1(5.3)$ & $1(9.1)$ & $0(0.0)$ & 1.000 \\
\hline DVT in subclavian vein & $0(0.0)$ & $0(0.0)$ & $0(0.0)$ & n.a. \\
\hline DVT in internal jugular vein & $9(47.4)$ & $3(27.3)$ & $6(75.0)$ & 0.070 \\
\hline DVT in other vein & $5(26.3)$ & $4(36.4)$ & $1(12.5)$ & 0.338 \\
\hline $\mathrm{PE}$ & $4(21.1)$ & $3(27.3)$ & $1(12.5)$ & 0.603 \\
\hline Diagnosed by DUS screening & $11(57.9)$ & $5(45.5)$ & $6(75.0)$ & 0.352 \\
\hline Symptomatic & $5(26.3)$ & $4(36.4)$ & $1(12.5)$ & 0.338 \\
\hline Treated with anticoagulation & $15(78.9)$ & $9(81.8)$ & $6(75.0)$ & 1.000 \\
\hline Treated with removal of the catheter & $7(36.8)$ & $1(9.1)$ & $6(75.0)$ & 0.006 \\
\hline Outcome & $(20.0)$ & & & \\
\hline ICU LOS & $13.0(5.0-21.0)$ & $8.0(5.0-16.0)$ & $20.0(11.5-35.5)$ & 0.062 \\
\hline Hospital LOS & $19.0(13.0-30.0)$ & $19.0(8.0-24.0)$ & $24.5(13.0-54.8)$ & 0.272 \\
\hline ICU and hospital mortality & $3(15.8)$ & $3(27.3)$ & $0(0.0)$ & 0.228 \\
\hline Mortality 1 year & $5(26.3)$ & $4(36.4)$ & $1(12.5)$ & 0.338 \\
\hline \multicolumn{5}{|c|}{ 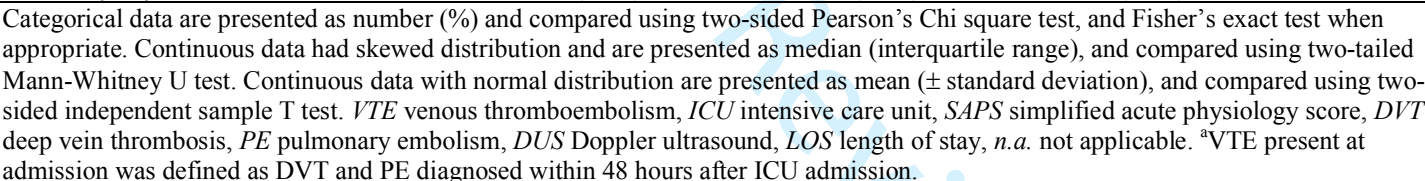 } \\
\hline
\end{tabular}

